\title{
Induction of Motor Neuron Sprouting in vivo by Ciliary Neurotrophic Factor and Basic Fibroblast Growth Factor
}

\author{
Mark E. Gurney, Hirotaka Yamamoto, and Young Kwon \\ Department of Cell, Molecular, and Structural Biology, Northwestern University Medical School, Chicago, Illinois 60611
}

\begin{abstract}
Ciliary neurotrophic factor (CNTF) and basic fibroblast growth factor (bFGF) were tested for effects on sprouting by motor neurons innervating the adult mouse gluteus muscle. Factors were delivered by subcutaneous injection directly over the surface of the superior gluteus muscle once daily for 7 $d$ and then end plates and axons were visualized by combined silver and cholinesterase staining. CNTF (500 ng daily) induced sprouting both from end plates and from the subset of nodes of Ranvier that are closest to the end plate. The effect of CNTF was potentiated twolold by coadmìnistration of bFGF at doses of 2-20 ng daily, whereas treatment with bFGF alone failed to induce sprouting from either end plates or nodes of Ranvier. The sprouting stimulus delivered by the factors showed limited penetrance into the muscle and restricted lateral spread from the injection site.
\end{abstract}

Two types of trauma induce motor neuron sprouting in muscle, partial denervation and paralysis. These induce sprouting both from end plates and from nodes of Ranvier. At least two physiological signals have been proposed to control sprouting (Brown et al., 1981). One is produced by muscle as a consequence of paralysis, and the other is produced within intramuscular nerves due to the presence of degenerating axons.

The evidence that muscle is the source of the paralysis-induced signal for sprouting includes the following. First, paralysis of muscle by blockade of axonal conduction with TTX (Brown and Ironton, 1977), blockade of ACh release by botulinum toxin (Duchen, 1970), and blockade of ACh action by $\alpha$-bungarotoxin (Holland and Brown, 1980) all induce sprouting from motor axon terminals. Since all of these manipulations have only one effect in common, induction of muscle paralysis, paralyzed muscle is likely to be the source of the signal for terminal sprouting. Second, the induction of sprouting by botulinum toxin can be blocked by restoring contractile activity in the paralyzed muscle through direct electrical stimulation (Brown et al., 1980a). Partial denervation also induces sprouting from undamaged motor axon terminals, and this too can be blocked by electrical stimulation (Ironton et al., 1978).

The strongest stimulus for nodal sprouting, in contrast, is the presence of degenerating axons (Brown et al., 1980a). Partial denervation induces nodal sprouting from undamaged axons

\footnotetext{
Received Jan. 3, 1992; revised Mar. 18, 1992; accepted Mar. 25, 1992.

This work was supported by NIH/NINCDS Grant 2PO1 NS21442 (M.E.G.) and by the Northwestern University Medical Scientist Training Program (Y.K.).

Correspondence should be addressed to Mark Gurney, Ph.D., Department of Cell, Molecular, and Structural Biology, Northwestern University Medical School, 303 East Chicago Avenue, Chicago, IL 60611.

Copyright (C) 1992 Society for Neuroscience $0270-6474 / 92 / 123241-07 \$ 05.00 / 0$
}

within intramuscular nerves. The nodal sprouts invade pathways left by degenerating axons and frequently grow along the trail of debris out to denervated end plates (Brown et al., 1982). Electrical stimulation of partially denervated muscle does not prevent nodal sprouting, which suggests that the stimulus for nodal sprouting does not come from paralyzed muscle, but may be produced within the damaged nerve (Ironton et al., 1978). Additional evidence that damaged nerve produces a stimulus for sprouting has been provided by Aguayo and others. Fragments of peripheral nerve implanted into the ENS induce sprouting of central axons into the graft (David and Aguayo, 1981) and induce sprouting by undamaged motor axons when implanted over the frog pectoral muscle (Diaz and Pecot-Dechavassine, 1990).

Although such biological manipulations define some of the cellular elements involved in sprouting, they do not define the molecular identity of the sprouting stimulus. Nor do they rule between the competing hypotheses that the stimulus for sprouting produced by paralyzed muscle is the same as or different from the stimulus for nodal sprouting produced by damaged nerve. For example, although botulinum toxin does not induce nodal sprouting deep within intramuscular nerves, it does induce sprouting from the last true node of Ranvier that is closest to the end plate (Hopkins et al., 1981). Since tight junctions within the perineurium sheathing intramuscular nerves form a barrier to diffusion of macromolecules (Low, 1976), a soluble signal for sprouting released by paralyzed muscle may not have equal access to nodes of Ranvier at different distances from the end plate. Thus, the same factor or set of factors could elicit both nodal and terminal sprouting. Differences in the type of sprouting elicited by paralysis or partial denervation may simply be due to the site of synthesis or accessibility to the factor.

Motor neuron sprouting may be controlled in part by the release of soluble cytokines or neurotrophic factors from muscle fibers, muscle satellite cells, or cellular elements of intramuscular nerves. Candidate factors that may regulate sprouting in vivo include ciliary neurotrophic factor (CNTF), basic fibroblast growth factor (bFGF), and insulin-like growth factor 2 (IGF-2). Both CNTF and bFGF support the survival and growth in culture of highly purified chick motor neurons (Arakawa et al., 1990), as do insulin and IGF-1 and IGF-2 although to a lesser extent (Arakawa et al., 1990; Caroni and Grandes, 1990). Treatment with CNTF also supports the survival of spinal motor neurons in vivo. Exogenous CNTF preserves perinatal facial motor neurons in rats from axotomy-induced cell death (Sendtner et al., 1990) and rescues embryonic chick motor neurons from programmed cell death (Oppenheim et al., 1991).

Several lines of evidence indicate that IGF-2 may participate 
in the regulation of motor neuron sprouting in vivo. First, denervation and paralysis increases expression of IGF-2 mRNA in skeletal muscle (Ishii, 1989). Second, treatment of adult mouse gluteus muscles with IGF-2 induces motor neuron sprouting (Caroni and Grandes, 1990). IGF-2 induces sprouting primarily from nodes of Ranvier as opposed to sprouting from end plates. It also induces GAP-43 expression by intramuscular nerves; induces interstitial accumulation of $\mathrm{J} 1$, but not N-CAM, immunoreactivity (Caroni and Grandes, 1990); and is a mitogen for muscle interstitial cells (Allen and Rankin, 1990).

We now show that CNTF acts in adult mice to induce sprouting from motor axon terminals and from the subset of nodes of Ranvier that are closest to the motor end plate. Its effects are facilitated by coadministration of bFGF, while bFGF alone fails to induce sprouting. Thus, the effects of CNTF and bFGF are synergistic in the assay. The sprouting stimulus delivered by subcutaneous injections of CNTF plus bFGF is highly localized. It showed limited penetration into the muscle and restricted lateral spread from the injection site.

\section{Materials and Methods}

Preparation of recombinant $C N T F$. Recombinant CNTF was expressed in Escherichia coli (Gurney and Yamamoto, 1991) from a CNTF cDNA that was cloned from rat C6 glioma cells using amplificatior "y the polymerase chain reaction with oligonucleotide primers derived from the published sequence (Stockli et al., 1989). The cDNA was inserted into a pET $1 \mathrm{ld}$ vector behind a T7 phage promoter (Studier et al., 1990) for expression in $E$. coli BL21 (DE3) that carry a T7 RNA polymerase gene under the control of an inducible lacUV 5 promoter. After induction $4 \mathrm{hr}$ with $0.5 \mathrm{~mm}$ isopropyl- $\beta$-thiogalactopyranoside, CNTF was obtained as an insoluble aggregate at levels approaching $70 \%$ of total $E$. coli protein. After extraction into guanidine, renaturation, and purification by anion-exchange chromatography and gel filtration, the yield of biologically active CNTF was nearly $50 \mathrm{mg} / 100 \mathrm{ml}$ culture. Endotoxin was $<0.06 \mathrm{EU} / \mathrm{mg}$ CNTF after purification (Limulus amebocyte lysate test kit, Whittaker Bioproducts) and was determined for each batch of CNTF. N-terminal sequence analysis of the purified CNTF was consistent with the sequence deduced from the cDNA through 11 sequenator cycles. The sequence acquired was AFAEQTPLTLH, which indicates that the methionine specified by the initiation codon has been cleaved from the $\mathrm{N}$-terminus of the protein. The amino acid composition of the purified protein was also consistent with the composition predicted by the cDNA sequence. Bioactivity of the purified CNTF was consistent with values reported in the literature (Squinto et al., 1990), with an $\mathrm{ED}_{50}$ on cultured chick ciliary neurons of $100 \mathrm{pg} / \mathrm{ml}$ (Gurney and Yamamoto, 1991). Batches of CNTF were monitored periodically for retention of biological activity on cultured chick ciliary neurons.

Protocol for injection of factors. The gluteus muscle in the mouse covers the dorsolateral surface of the thigh. It comprises a thin sheet of muscle fibers that radiate anteriorly from a tendon inserting along the femur. The gluteus muscle is divided into two muscles, the superior gluteus and inferior gluteus muscles. It joins along its lateral margin to the tensor facia latae (TFL), which extends almost to the knee. The muscle sheet is innervated by three nerves. From medial to lateral, these are the inferior glutcal nerve, the supcrior gluteal ncrve, and then the TFL nerve. The superior gluteal and TFL nerves enter the muscle sheet at the junction between the gluteal and TFL muscles, while the inferior gluteal nerve enters the medial margin of the muscle. Synapses are formed in a band across the middle of the muscle sheet.

For injection, male ICR mice of $20-24 \mathrm{gm}$ were anesthetized lightly by inhalation of metofane (Pitman-Moore). Subcutaneous injections of $10 \mu \mathrm{l}$ vol were placed over the surface of the superior gluteus muscle approximately $1 \mathrm{~cm}$ lateral to the spinal column. Injections were delivered with a $10 \mu 1$ Hamilton syringe (Hamilton Co., Reno, NV). A separate, cleaned syringe was used for each treatment group. Injections were made daily for $7 \mathrm{~d}$. Five mice were injected per treatment group.

bFGF was purchased from $R \& D$ Biosystems. CNTF was prepared as described above. The factors were dissolved in sterile phosphate-buffered saline containing bovine serum albumin at $100 \mu \mathrm{g} / \mathrm{ml}$ (Fraction V, Sigma-Aldrich Chemical Co.). Factors were aliquoted for injection in single dosage vials and quick frozen at $-70^{\circ} \mathrm{C}$. Aliquots were thawed once and discarded.

Protocol for silver and cholinesterase staining of muscles. The protocol for staining treated muscles was adapted from Hopkins and Slack (1981). The mice were anesthetized with metofane and then were killed by cervical dislocation. For staining, the gluteus muscle was dissected from the animal, pinned on a small square of dental wax, and then fixed in situ with $4 \%$ paraformaldehyde in $100 \mathrm{~mm}$ sodium phosphate $(\mathrm{pH} 7.5$ ) containing $5 \%$ sucrose and $1 \%$ dimethyl sulfoxide at $4^{\circ} \mathrm{C}$ for $1 \mathrm{hr}$. After one wash in buffer and two $5 \mathrm{~min}$ washes in water, the muscles were reacted for cholinesterase at $4^{\circ} \mathrm{C}$ for $20 \mathrm{~min}$ in $1.7 \mathrm{~mm}$ acetylthiocholine iodide, $30 \mathrm{~mm}$ sodium maleate, $5 \mathrm{~mm}$ sodium citrate, $3 \mathrm{~mm}$ copper sulfate, and $0.5 \mathrm{~mm}$ potassium ferricyanide ( $\mathrm{pH} \mathrm{6.0)}$ ). After three washes in water, they were treated $10 \mathrm{~min}$ at room temperature (RT) with 7.5 mM potassium ferricyanide. After four washes in water, dehydration in ethanol for $1 \mathrm{hr}$ at RT, and then rehydration to water, the muscles were stained $20 \mathrm{~min}$ at $\mathrm{RT}$ in $1 \%$ silver nitrate in $20 \mathrm{~mm}$ sodium borate buffer $(\mathrm{pH} 7.0 \pm 0.2)$. After four washes with water, they were developed in $400 \mathrm{~mm}$ sodium sulfite, $90 \mathrm{~mm}$ hydroquinone, and $20 \mathrm{~mm}$ borax while observing development through a dissecting microscope. The stained muscles were cleared in xylene and mounted between two cover slips in Permount (Roswell Park Memorial Institute). Common staining artifacts were staining of superficial but not deep end plates, and staining of connective tissue and capillaries. The former was corrected by lengthening the incubation of the muscle in silver nitrate solution to $20 \mathrm{~min}$ (from $15 \mathrm{~min}$ ). To compensate for changes in agrophylia due to the increased synthesis of capillaries and collagen fibrils caused by bFGF, we found it necessary to increase the $\mathrm{pH}$ of the silver staining solution from $\mathrm{pH} 6.5$ to $\mathrm{pH} 7.0$. A pH of 7.0 gave optimal staining of axons with the least staining of capillaries and collagen fibrils. A slightly more acidic silver solution increased the staining of capillaries and slightly more basic conditions favored staining of collagen fibrils.

Data analysis. Injections and coding of muscles were performed by one member of the research team and the muscles were stained and scored for sprouts by a second, blinded observer. Data were collected from 85 mice comprising 17 treatment groups of five mice each. The gluteus muscles from 84 of the mice were stained successfully. Data were discarded from one mouse due to poor staining of the gluteus muscle. Deletion of data was made prior to breaking the code for assignment to a treatment group. End plates innervated by one or more dorsal branches of the superior gluteal nerve were scored for the presence of sprouts at $250 \times$ magnification with a Planapo $25 \times$ objective. Counts were begun where the superior gluteal nerve entered the muscle and then followed the nerve medially until the muscle spindle innervated by the superior gluteal nerve was reached. Intramuscular branches of the supcrior gluteal nerve end in clusters of nerve terminals and all of the clearly stained nerve terminals in each cluster were scored for sprouts. From 50 to 100 end plates were scored in each muscle. Quantitative data are expressed as the percentage of terminals with sprouts (mean \pm $\mathrm{SEM} ; n=5$ ). Statistical comparisons were made using a one-tailed $t$ test. The restricted spread of the sprouting stimulus was recognized after partial analysis of the experiment. So that uniform counting criteria would be used for all treatment groups, at the conclusion of data collection, all of the muscles were scored blind a second time (data in Fig. $2 A, B$; Table 1). Table 2 presents data on the frequency of end plates with sprouts for the inferior gluteus, superior gluteus, and tensor facia latae muscles. Counts were made across the complete width of each muscle within the first $30 \mu \mathrm{m}$ from the dorsal or ventral surface of each muscle. Counts of nodal sprouts were made separately. Data are expressed as the percentage of preterminal axons with nodal sprouts (mean \pm SEM; $n=5$ ). Counts were made across the complete width of the superior gluteus muscle within $30 \mu \mathrm{m}$ of its dorsal surface. From 100 to 200 preterminal axons were scored per muscle.

\section{Results}

\section{Effects of CNTF and $b F G F$ on terminal sprouting}

Motor neuron sprouting was induced by treating adult mouse gluteus muscles with subcutaneous injections of CNTF or CNTF coadministered with bFGF (CNTF+bFGF). Examples of silver and cholinesterase stained motor terminals in adult gluteus muscles are shown in Figure 1. The figure illustrates examples of both terminal sprouting (Fig. 1b,c) and sprouting from the node of Ranvier closest to the motor end plate (Fig. $1 d, e$ ). The sprouts 


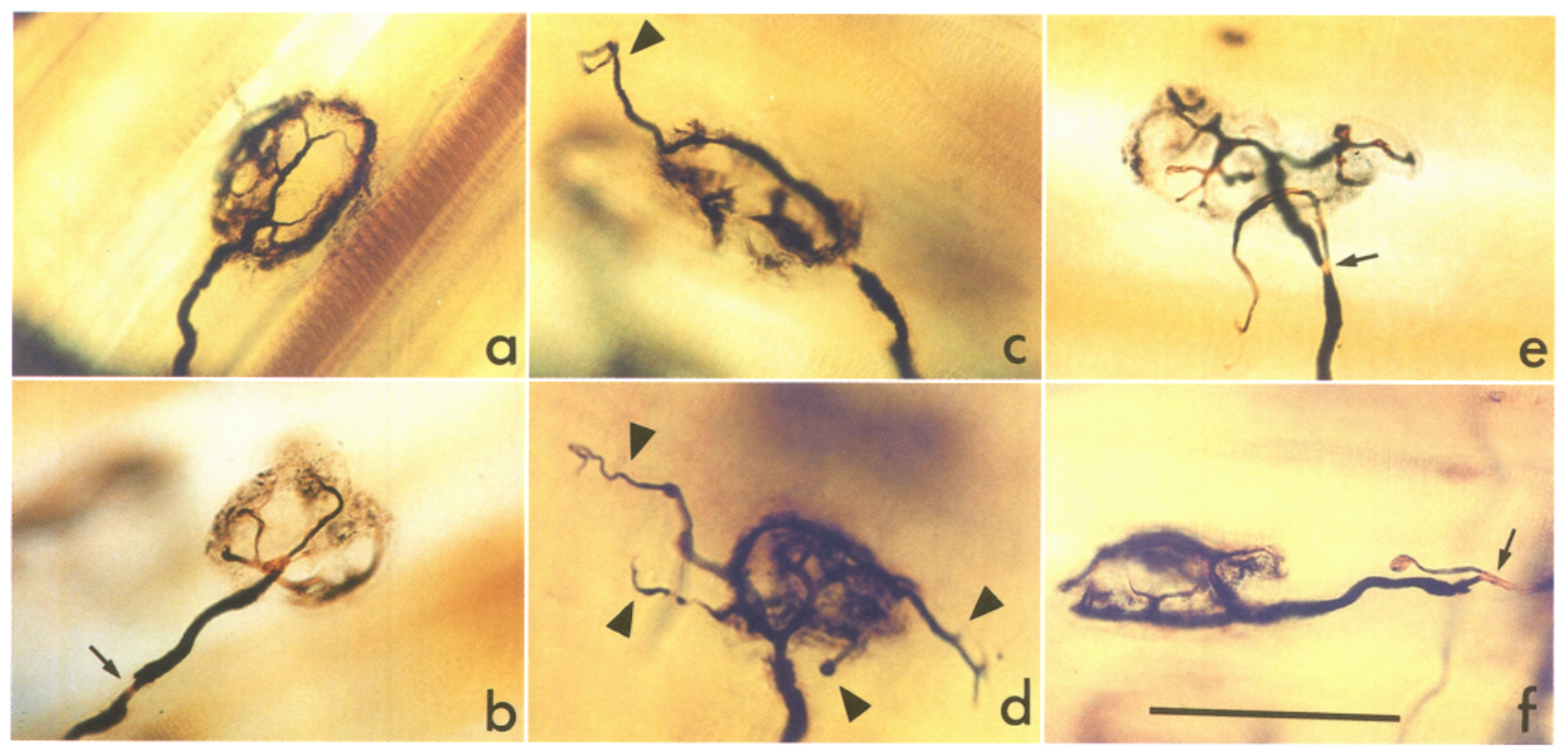

Figure 1. Silver- and cholinesterase-stained end plates from the adult mouse superior gluteus muscle. The silver stain reveals fine details of the organization of filaments within the preterminal axon and synaptic terminal. The filament bundles branch profusely as they enter the axon terminal and are colinear with filaments within the sprouts. The cholinesterase reaction product forms a granular precipitate that outlines the end plate. The small arrows in $b, e$, and $f$ indicate the constriction in the axon filament system that occurs at nodes of Ranvier. The myelin sheath is not stained in this preparation. $a$ and $b$, Nonsprouting end plates from muscles treated with BSA. $c$ and $d$, End plates with sprouts from muscles treated with $\mathrm{CNTF}+\mathrm{bFGF}$. The sprouts are marked by arrowheads. $e$ and $f$, Nodal sprouts observed in muscles treated with CNTF+bFGF. The sprouts originate from the last true node of Ranvier that is closest to the endplate (arrows). Scale bar, $50 \mu \mathrm{m}$.

are very thin along their length and frequently terminate in a small bulb. The bulbs are growth cones whose filopodia make extensive contacts with the basal lamina covering the surface of the muscle fiber as the sprouts grow out from the end plate (Torigoe, 1988). The morphology of sprouts induced by CNTF or $\mathrm{CNTF}+\mathrm{bFGF}$ is indistinguishable from sprouts induced by botulinum toxin (see, e.g., Hopkins et al., 1981). CNTF, bFGF, and CNTF+ bFGF had no discernable effect on sensory afferents within the gluteus muscle.

Sprouting from end plates was the predominant type of sprouting in muscles that were treated with either CNTF or $\mathrm{CNTF}+\mathrm{bFGF}$ (Table 1). In untreated muscles, or muscles treated with control vehicle containing $1 \mu \mathrm{g}$ BSA per day, no more than $1 \%$ of the end plates innervated by dorsal branches of the superior gluteus nerve had sprouts. In muscles treated with 500 ng CNTF/d, the percentage of end plates with sprouts increased more than 20-fold. The effect of CNTF was facilitated 2.4-fold by coadministration of bFGF (Fig. $2 A$ ), while treatment with bFGF alone at any dose tested failed to induce sprouting (Fig. $2 B$ ). Thus, the effect of bFGF with CNTF was synergistic rather than additive. Optimal doses for induction of terminal sprouting were either $500 \mathrm{ng}$ CNTF with $2 \mathrm{ng}$ bFGF or $1 \mu \mathrm{g} \mathrm{CNTF}$ with $10 \mathrm{ng}$ bFGF. At those doses, sprouting was elicited at up to $30 \%$ of the end plates innervated by dorsal branches of the superior gluteal nerve (Fig. $2 A$ ). Over the range of CNTF doses tested, a dose-response relation was observed. Reduced levels of sprouting were observed with both lower and higher doses of CNTF. With CNTF dosages held constant at 500 ng per day, sprouting increased with bFGF dosage up to $20 \mathrm{ng}$ bFGF per day (Fig. $2 B$ ), $20 \mathrm{ng}$ bFGF per day induced formation of new

Table 1. Comparison of sprouting from end plates versus nodes of Ranvier in dorsal branches of the superior gluteal nerve

\begin{tabular}{llllr}
\multicolumn{2}{l}{ Treatment } & & \\
\cline { 2 - 5 } & BSA & FGF & \multicolumn{1}{l}{ CNTF } & \multicolumn{1}{c}{ CNTF } \\
& bFGF \\
\hline End plates with sprouts & $0.4 \pm 0.2$ & $0.2 \pm 0.2^{c}$ & $12.7 \pm 3.5^{a}$ & $30.3 \pm 2.9^{a, d}$ \\
Nodes of Ranvier with sprouts & $0.4 \pm 0.2$ & $1.0 \pm 0.3^{c}$ & $1.9 \pm 0.6^{b}$ & $4.6 \pm 0.6^{a . e}$
\end{tabular}

Treatments were vehicle containing $1 \mu \mathrm{g}$ BSA daily, $2 \mathrm{ng}$ bFGF daily, $500 \mathrm{ng}$ CNTF daily, or $500 \mathrm{ng}$ CNTF plus $2 \mathrm{ng}$ bFGF daily. Data are mean percentage $\pm \operatorname{SEM}(n=5)$.

${ }^{a} p \leq 0.01$ vs BSA.

${ }^{b} p \leq 0.05$ vs BSA

'Not significant vs BSA.

${ }^{d} p<0.02$ vs CNTF

e $p<0.05$ vs CNTF. 
A

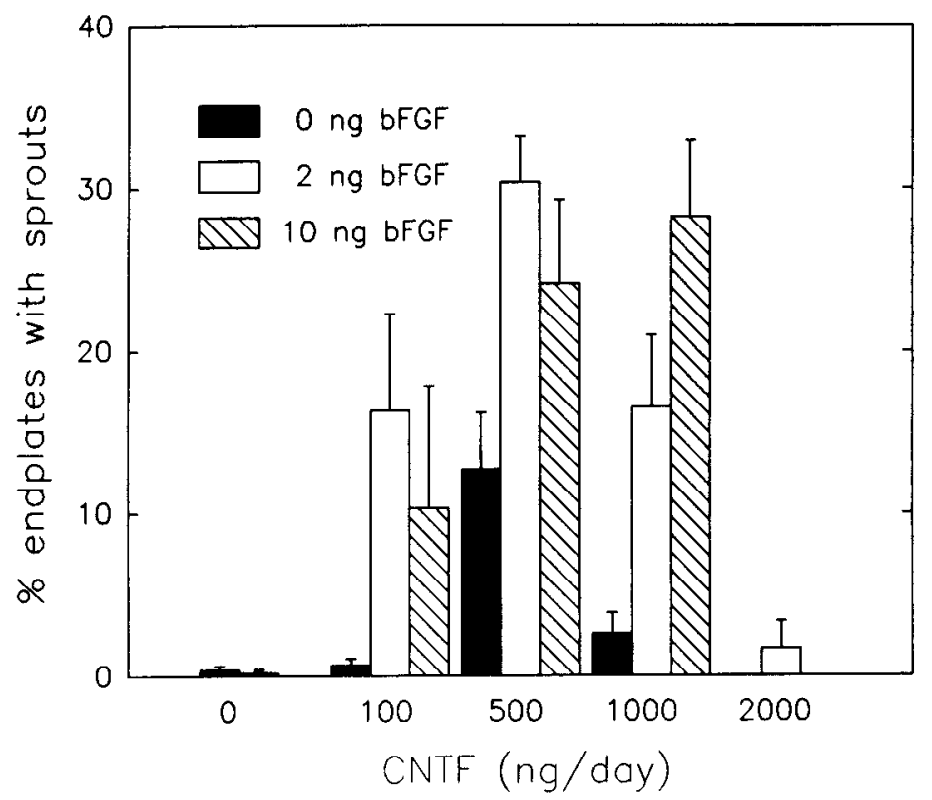

B

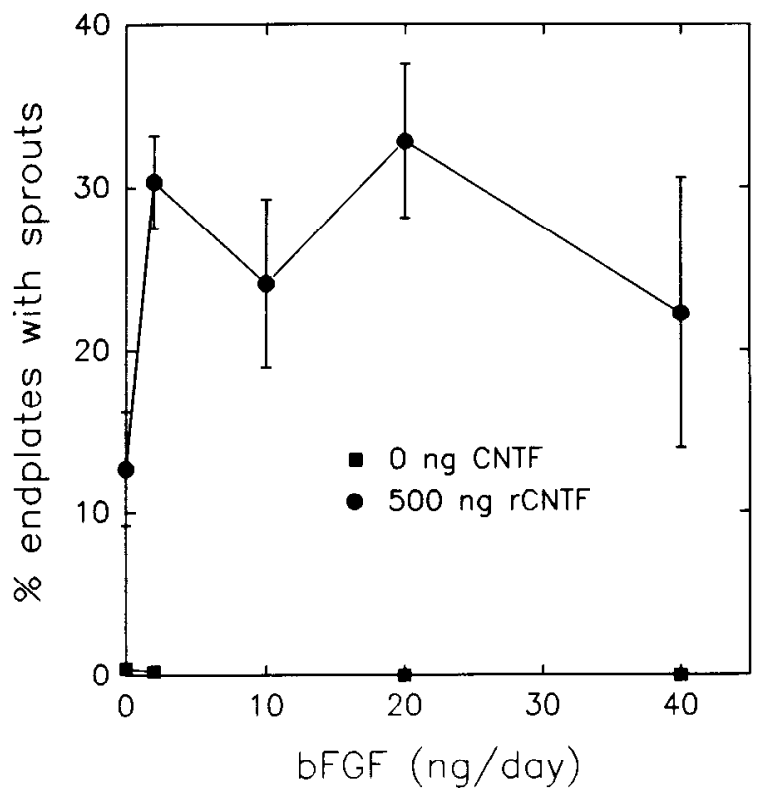

Figure 2. A, Dose-response relationship for induction of sprouting by bFGF and CNTF at end plates innervated by dorsal branches of the superior gluteal nerve. $B$, Dose-response relationship for facilitation by bFGF of sprouting induced by CNTF at end plates innervated by dorsal branches of the superior gluteal nerve. Error bars are mean $\pm \operatorname{SEM}(n=5)$.

capillaries and increased numbers of collagen fibrils within the treated muscle, but no sprouting was induced in the absence of CNTF. The increase in number of agryphilic collagen fibrils was particularly troublesome since they obscured visualization of end plates.

We tested the combination of bFGF and CNTF in vivo because we had found striking synergy of bFGF with CNTF in vitro (Gurney and Yamamoto, 1991). Since spinal motor neurons express FGF receptor gene transcripts (Wanaka et al., 1990), bFGF may act directly on motor neurons in vivo. Alternatively, since bFGF alone does not induce sprouting, it may act indirectly by modulating matrix synthesis or degradation (Rifkin and Moscatelli, 1989), or hy acting as a mitogen for muscle interstitial cells (Allen and Rankin, 1990). Several matrix or cell surface components that influence neurite extension or adhesion in vitro are expressed on the surface of muscle fibers and by muscle interstitial cells. These include the cell adhesion molecules N-CAM (Couvalt and Sanes, 1986) and tenascin (Sanes et al., 1986). Their expression is modulated by muscle paralysis or partial denervation in ways that suggest these molecules may play a role in terminal or nodal sprouting in vivo. They may also be targets of modulation by bFGF and/or CNTF in this assay.

\section{Effects of CNTF and bFGF on nodal sprouting}

The only nodes of Ranvier that developed sprouts after treatment with CNTF or CNTF plus bFGF were the last true nodes of Ranvier that were closest to the end plate. We never detected sprouting from nodes of Ranvier located within intramuscular nerves. Occasional end plates in muscle are innervated by axons that divide into two myelinated terminal branches. Nodal sprouts could be distinguished from branched axons by their finer caliber and by the presence of clubbed or bulbous endings at their tips that presumably are growth cones. Branched axons were thicker in caliber and ended in a terminal arbor at the end plate.
Figure $1 e$ illustrates a nodal sprout that arose from the last node of Ranvier closest to the end plate and that then grew to the adjacent end plate and across the muscle fiber surface. In Figure $1 f$, the nodal sprout appears to be growing along the surface of a myelinating Schwann cell that is not visualized by the stain. Most nodal sprouts grew toward the adjacent end plate. In one extreme case, we observed a nodal sprout follow the preterminal axon away from the end plate, and then turn and follow a second axon toward its end plate. Fewer than $1 \%$ of the preterminal axons examined had nodal sprouts in control muscles treated with $1 \mu \mathrm{g}$ BSA per day (Table 1). Treatment with $500 \mathrm{ng}$ CNTF daily increased the frequency of nodal sprouting by fourfold. As was the case for sprouting from end plates, coadministration of $2 \mathrm{ng}$ bFGF daily potentiated the effect of CNTF more than twofold, while treatment with bFGF only had no significant effect on nodal sprouting. Because nodal sprouts occurred so infrequently, we did not quantitate dose-response relationships further.

\section{Restricted spread of the sprouting stimulus}

During the analysis of the experiment, it became apparent that sprouting was highly localized in the muscle. Sprouting occurred primarily in the superior gluteus muscle and mostly at end plates of superficial muscle fibers located on the dorsal surface of the muscle (Fig. 1). This was unexpected since injection of a polypeptide toxin such as botulinum toxin type $A$ induces sprouting throughout the depth of the muscle. In fresh-frozen, cryostat sections, the superior gluteus muscle is about $500 \mu \mathrm{m}$ thick. It consists of 10-12 layers of muscle fibers that average $60-70 \mu \mathrm{m}$ in diameter. During dehydration, clearing, and mounting in Permount, the muscle shrinks to $100-110 \mu \mathrm{m}$ in thickness. By using a Planapo $25 \times$ objective, we optically sectioned the muscle and scored end plates within $30 \mu \mathrm{m}$ of the dorsal or ventral surfaces of the inferior gluteus muscle for the occurrence of sprouting. Counts were made in muscles that had been treated 
Table 2. Frequency of end plates with sprouts in the inferior gluteus, superior gluteus, and TFL muscles after treatment with $500 \mathrm{ng}$ CNTF and 2 ng bFGF

\begin{tabular}{llcl} 
& Inferior gluteus & Superior gluteus & TFL \\
\hline Dorsal & $10.5 \pm 2.5$ & $27.9 \pm 6.1^{\circ}$ & $2.8 \perp 0.9$ \\
Ventral & & $7.5 \pm 2.6$ & \\
\hline
\end{tabular}

The percentage of end plates with sprouts within $30 \mu \mathrm{m}$ of the dorsal or ventral surfaces of the muscle sheet was determined. Data are mean percentage \pm SEM $(n=5)$.

${ }^{a} p \leq 0.01$ vs inferior or TFL, $p \leq 0.005$ dorsal vs ventral.

with $500 \mathrm{ng}$ CNTF and $2 \mathrm{ng}$ bFGF per day. More than twice as many end plates on the dorsal surface of the gluteus muscle were sprouting in comparison to the ventral surface (Table $2 ; p$ $<0.005)$. Thus, the sprouting stimulus delivered by CNTF+bFGF penetrated poorly into the gluteus muscle.

To estimate the lateral spread of the sprouting stimulus delivered by injection of $500 \mathrm{ng}$ CNTF and $2 \mathrm{ng}$ bFGF per day, we scored end plates on the dorsal surfaces of the inferior gluteus, superior gluteus, and TFL muscles (Table 2). We also charted the location of end plates with sprouts in the shect of muscle by using a microscope whose stage was equipped with sensors of its $x-y$-position (Fig. 3). Synapses are made by the inferior gluteal, superior gluteal, and TFL nerves in a broad, medial to lateral band across the width of the muscle sheet. Sprouting was more prevalent on the dorsal surface of the superior gluteus muscle as compared to the inferior gluteus or TFL muscles (Table $2 ; p \leq 0.01$ ). The region where sprouting was most prevalent corresponded to the the site of injection. The restriction of sprouting to that site may have been due to the small injection volume of $10 \mu \mathrm{l}$ used in the study. However, injection of botulinum toxin in $10 \mu \mathrm{l}$ induces sprouting across the width of the gluteus muscle as well as paralysis in adjacent muscles of the abdominal wall. Botulinum toxin type A consists of two, disulfide-linked polypeptide chains of approximately 50,000 and 100,000 Da (Binz et al., 1990), so the size of CNTF is unlikely to account for the restricted spread of the sprouting stimulus from the injection site.

\section{Discussion}

Data that support the hypothesis that CNTF is a growth factor for motor neurons include the following. First, it allows the survival and growth of highly purified spinal cord motor neurons in culture (Arakawa et al., 1990). The effects of CNTF are additive with those of bFGF in the culture system. Bloch-Gallego et al. (1991), however, failed to show that CNTF or bFGF supported chick motor neuron survival in culture, but their culture system failed to maintain motor neuron number in control conditions past $2 \mathrm{~d}$ in culture. Second, treatment with CNTF rescues perinatal facial motor neurons (Sendtner et al., 1990) and embryonic spinal cord motor neurons (Oppenheim et al., 1991) that otherwise would die during ontogenetic cell death or after injury. Our results also support the hypothesis by showing that CNTF induces motor neuron sprouting from end plates and from a subset of nodes of Ranvier in the adult, and that its effects are potentiated by bFGF. A caveat to these data is that experiments performed in vivo do not distinguish between direct and indirect effects of CNTF on the neuronal population under study.

If endogenous CNTF functions as a growth factor for molor neurons in $v i v c$, it cannot be due to a simple (i.e., direct) com-

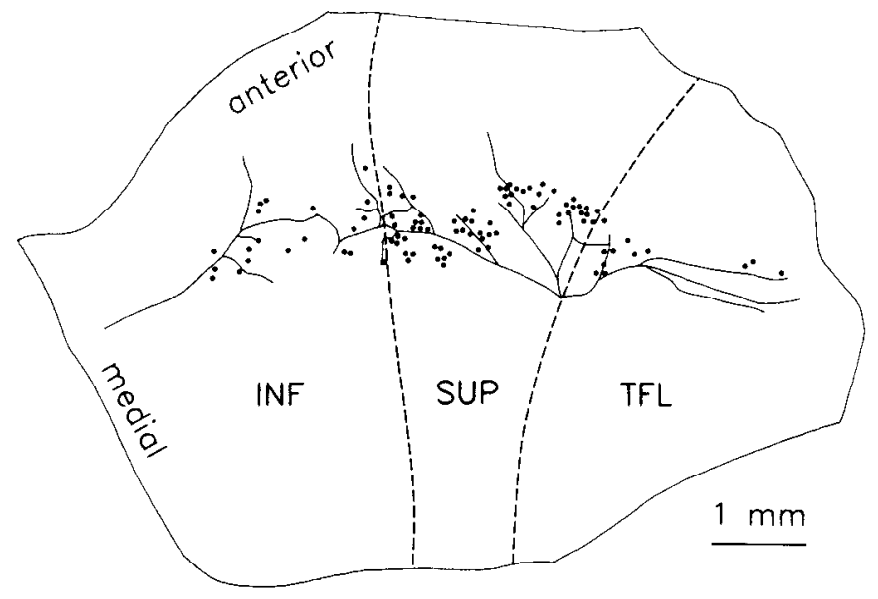

Figure 3. Locations of endplates with sprouts (dots) in the gluteus and TFL muscles after daily administration of $500 \mathrm{ng}$ CNTF and $2 \mathrm{ng}$ bFGF. The divisions between the inferior $(I N F)$ and superior $(S U P)$ gluteus muscles and the TFL are indicated by the broken lines. Each muscle is innervated by a separate nerve, although there is some overlap between the fields of innervation by the superior and inferior gluteal nerves. Subcutaneous injections were placed roughly over the surface of the superior gluteus muscle. The medial margin of the muscle inserts along the spinal column, while the posterior margin attaches to the femur. The superior gluteal nerve enters the muscle from the ventral surface where the superior gluteus joins the TFL muscle. Synapses are made by each of the nerves in a broad, uniform band across the width of the muscle sheet from medial to lateral.

munication between muscle and nerve because the gene for CNTF is not expressed in muscle (Stockli et al., 1989). CNTF mRNA is expressed in sciatic nerve (Lin et al., 1989), perhaps within Schwann cells, but it so far has not been detected in muscle fibers. However, effects of paralysis and partial denervation on CNTF mRNA expression in muscle still need to be addressed. Expression of CNTF mRNA may be upregulated by physiological events that induce sprouting, or alternatively, treatment with CNTF could substitute for a homologous factor that is expressed in muscle. Eckenstein et al. (1990), for example, have isolated a second, homologous neurotrophin whose biological activity overlaps with CNTF.

Alternatively, since CNTF is present in peripheral nerve (Lin et al., 1989; Stockli et al., 1989), muscle fibers may not participate at all in the stimulus for sprouting. Cellular elements within intramuscular nerves such as Schwann cells may sense nerve damage or muscle paralysis and release CNTF, which then acts on the motor end plate. For example, infiltration of activated macrophages into damaged peripheral nerve induces NGF synthesis by both Schwann cells and fibroblasts (Heumann et al., 1987). The same stimulus could induce release of CNTF from damaged nerve. It is less easy to understand how Schwann cells could sense muscle paralysis, or how direct electrical stimulation of muscle, which suppresses sprouting from end plates (Ironton et al., 1978; Brown et al., 1980a), could suppress the release of CNTF from Schwann cells.

Another unknown in the regulation of sprouting is the expression of CNTF receptors in muscle. The subunit of the neuronal CNTF receptor cloned by Davis et al. (1991) is a 72,000 Da glycoprotein (gp72 $2^{\text {NTF-R }}$ ). The gene for gp72 CNTF-R is expressed in skeletal muscle as well as in one or more muscle cell lines. The deduced amino acid sequence of $\mathrm{gp} 72^{\mathrm{NTr}-\mathrm{R}}$ lacks a transmembrane domain and instead is anchored to the cell sur- 
face via a glycosyl-phosphatidyl inositol linkage. Phospholipase $\mathrm{C}$ treatment cleaves gp $72^{\mathrm{CNTF}-\mathrm{R}}$ from the surface of transfected cells and from a neural cell line (SY5Y) that expresses endogenous gp $72^{\text {CNTF-R }}$. The sequence of $g p 72^{\text {CNTF-R }}$ is homologous to one subunit of the interleukin-6 receptor, which has led Davis et al. (1991) to propose a two-subunit model for the functional CNTF receptor. At least one binding site for CNTF is contributed to the receptor by $\mathrm{gp} 72^{\mathrm{CNTF}-\mathrm{R}}$, while a second, transmembrane glycoprotein subunit is believed to contribute a tyrosine kinase catalytic domain. This has two consequences for understanding the biology of CNTF. First, gp $72^{\text {CNTF-R }}$ may be cleaved from the cell surface and released in a soluble form that retains CNTF binding. A soluble form of the low-affinity subunit of the NGF receptor is secreted in urine, for example, and its amount is increased by trauma to peripheral nerves (DiSteffano and Johnson, 1988). Second, cells that express gp $72^{\text {CNTF-R }}$ will bind CNTF, but may not have a functional response to CNTF if the gene for the proposed tyrosine kinase subunit is not coordinately expressed.

The idea that cells may express CNTF binding sites, but not functional CNTF receptors, is reminiscent of the expression of the low-affinity NGF receptor subunit by Schwann cells. After nerve crush or transection, Schwann cells distal to the trauma express the low-affinity subunit of the NGF receptor (Taniuchi et al., 1988). When nerve regeneration occurs, NGF receptor expression is suppressed as axons grow into the distal nerve. Binding affinity of NGF to the Schwann cell surface is in the nanomolar range, rather than in the picomolar range as found for functional receptors on responsive neurons. Taniuchi et al. (1988) argue that expression of low-affinity NGF receptors on Schwann cells increases the local concentration of NGF available to regenerating axons. Raivich et al. (1991) dispute that interpretation, in part because NGF receptor expression falls in regenerating neurons.

Expression of gp $72^{\text {CNTF-R }}$ by skeletal muscle could provide a mechanism whereby muscle fibers might accumulate CNTF that is synthesized at a distant site. It also may provide a mechanism that could limit the spread of a diffusible sprouting signal. Although most studies implicate the muscle fiber as the source of the stimulus for terminal sprouting, three studies indicate that the sprouting stimulus does not travel far within a muscle and that it does not travel between muscles (Betz et al., 1980; Brown et al., 1980b; Slack and Pockett, 1981). At most, the endogenous signal for terminal sprouting may travel 50-100 $\mu \mathrm{m}$ (Slack and Pockett, 1981). In our study, we found that subcutaneous injection of CNTF induced sprouting immediately beneath the site of injection. Thus, either CNTF is rapidly degraded after injection and biologically effective concentrations are only reached at the site of injection, or the injected factor is retained at the site of injection. To resolve this question, it should be possible to use CNTF tagged with a myc epitope (Squinto et al., 1990) to determine the range of diffusion of the factor after injection in vivo. If skeletal muscle fibers do in fact express gp $72^{\text {CNTF-R }}$ on their surface, that may provide a mechanism for retaining CNTF beneath the site of the injection. Partial denervation or paralysis might then indirectly regulate sprouting from end plates by influencing the expression or redistribution of $\mathrm{gp} 72^{\mathrm{CNTF}-\mathrm{R}}$.

Whereas CNTF induces sprouting primarily from motor end plates, IGF-2 induces sprouting primarily from nodes of Ranvier (Caroni and Grandes, 1990). Thus, at least three factors, CNTF, bFGF, and IGF-2, may act coordinately on the motor neuron to induce sprouting. These are synthesized by different cell types and may be available at different sites to the same neuron. One combination of factors may be available at the end plate, while a different combination may be accessible to nodes of Ranvier in peripheral nerves. Each combination of factors may differ in their cellular targets of action. One or more factors may induce a program for growth in the motor neuron, and a different combination may induce synthesis of matrix components or adhesion molecules by muscle fibers, muscle interstitial cells, or Schwann cells, that are needed to provide a substrate for the outgrowth of sprouts from end plates or nodes of Ranvier. Future experiments should now directly assess their roles as physiological mediators of motor neuron sprouting and regeneration.

\section{References}

Allen RE, Rankin LL (1990) Regulation of satellite cells during skeletal muscle growth and development. Proc Soc Exp Biol Med 194:81-86. Arakawa Y, Sendtner M, Thoenen H (1990) Survival effect of ciliary neurotrophic factor (CNTF) on chick embryonic motoneurons in culture: comparison with other neurotrophic factors and cytokines. $J$ Neurosci 10:3507-3515.

Betz WJ, Caldwell JH, Ribchester RR (1980) Sprouting of inactive nerve terminals in partially inactive muscles of the rat. J Physiol (Lond) 303:281-297.

Binz T, Kurazono H, Wille M, Frevert J, Wernars K, Niemann H (1990) The complete sequence of botulinum neurotoxin type $A$ and comparison with other clostridial neurotoxins. J Biol Chem 265:91539158.

Bloch-Gallego E, Huchet M, El M'Hamdi H, Xie F-K, Tanaka H, Henderson CE (1991) Survival in vitro of motoneurons identified or purified by novel antibody-based methods is selectively enhanced by muscle-derived factors. Development 111:221-232.

Brown MC, Ironton R (1977) Motor neurone sprouting induced by prolonged tetrodotoxin block of nerve action potentials. Nature 265: 459-461.

Brown MC, Holland RL, Ironton R (1980a) Nodal and terminal sprouting from motor nerves in fast and slow muscles of the mouse. J Physiol (Lond) 306:493-510.

Brown MC, Holland RL, Hopkins WG, Keynes RJ (1980b) An assessment of the spread of the signal for terminal sprouting within and between muscles. Brain Res 210:145-151.

Brown MC, Holland RL, Hopkins WG (1981) Motor nerve sprouting. Annu Rev Neurosci 4:17-42.

Brown MC, Hopkins WG, Keynes RJ (1982) Importance of pathway formation for nodal sprout production in partly denervated muscles. Brain Res 243:345-349.

Caroni P, Grandes P (1990) Nerve sprouting in innervated adult skeletal muscle induced by exposure to elevated levels of insulin-like growth factors. J Cell Biol 110:1307-1317.

Couvalt J, Sanes JR (1986) Distribution of N-CAM in synaptic and extrasynaptic portions of developing and adult skeletal muscle. J Cell Biol 102:716-730.

David S, Aguayo AJ (1981) Axonal elongation into peripheral nervous system "bridges" after central nervous system injury in adult rats. Science 214:931-933.

Davis S, Aldrich TH, Valenzuela DM, Wong V, Furth ME, Squinto SP, Yanacopoulos GD (1991) The receptor for ciliary neurotrophic factor. Science 253:59-63.

Diaz J, Pecot-Dechavassine M (1990) Nerve sprouting induced by a piece of peripheral nerve placed over a normally innervated frog muscle. J Physiol (Lond) 421:123-133.

DiSteffano PS, Johnson EM Jr (1988) Identification of a truncated form of the nerve growth factor receptor. Proc Natl Acad Sci USA $85: 270-274$.

Duchen LW (1970) Changes in motor innervation and cholinesterase localization induced by botulinum toxin in skeletal muscle of the mouse: differences between fast and slow muscle. J Neurol Neurosurg Psychiatry 33:40-54.

Eckenstein FP, Esch F, Holbert T, Blacher RW, Nishi R (1990) Purification and characterization of a trophic factor for embryonic pe- 
ripheral neurons: comparison with fibroblast growth factors. Neuron 4:623-631.

Gurney ME, Yamamoto H (1991) Expression of recombinant rat ciliary neurotrophic factor in Escherichia coli and its synergy with basic fibroblast growth factor. Cell Mol Neurosci 2:369-376.

Heumann R, Lindholm D, Bandtlow C, Meyer M, Radke MJ, Misko TP, Shooter E, Thoenen H (1987) Differential regulation of mRNA encoding nerve growth factor and its receptor in rat sciatic nerve during development, degeneration, and regeneration: role of macrophages. Proc Natl Acad Sci USA 84:8735-8739.

Holland RL, Brown MC (1980) Postsynaptic transmission block can cause terminal sprouting of a motor nerve. Science 207:649-650.

Hopkins WG, Slack JR (1981) The sequential development of nodal sprouts in mouse muscles in response to nerve degeneration. $J$ Neurocytol 10:537-556.

Hopkins WG, Brown MC, Keynes RJ (1981) Nerve growth from nodes of Ranvier in inactive muscle. Brain Res 222:125-128.

Ironton R, Brown MC, Holland RL (1978) Stimuli to intramuscular nerve growth. Brain Res 156:351-354.

Ishii DN (1989) Relationship of insulin-like growth factor II gene expression in muscle to synaptogenesis. Proc Natl Acad Sci USA 86: 2898-2902.

Lin L-FH, Mismer D, Lile JD, Armes LG, Butler ET, Vannice JL, Collins F (1989) Purification, cloning, and expression of ciliary neurotrophic factor (CNTF). Science 246:1023-1025.

Low NN (1976) The perineurium and connective tissue of peripheral nerve. In: The peripheral nerve (Landon DN, ed), pp 159-187. New York: Wiley.

Oppenheim RW, Prevette D, Qin-Wei Y, Collins F, MacDonald J (1991) Control of embryonic motoneuron survival in vivo by ciliary neurotrophic factor. Science 251:1616-1618.

Raivich G, Hellwegg R, Kreutzberg GW (1991) NGF receptor-mediated reduction in axonal NGF uptake and retrograde transport following sciatic nerve injury and during regeneration. Neuron $7: 151-$ 164 .
Rifkin DB, Moscatelli D (1989) Recent developments in the cell biology of basic fibroblast growth factor. J Cell Biol 109:1-6.

Sanes JR, Schachner M, Covault J (1986) Expression of several adhesive macromolecules (N-CAM, LI , J I, NILE, uvomorulin, laminin, fibronectin, and a heparin sulfate proteoglycan) in embryonic, adult and denervated adult skeletal muscle. J Cell Biol 102:420-431.

Sendtner M, Kreutzberg GW, Thoenen H (1990) Ciliary neurotrophic factor prevents the degeneration of motor neurons after axotomy. Nature 345:440-441.

Slack JR, Pockett S (1981) Terminal sprouting is a local response to a local stimulus. Brain Res 217:368-374.

Squinto SP, Aldrich TH, Lindsay RM, Morrissey DM, Panayotatos N, Bianco SM, Furth ME, Yancopoulos GD (1990) Identification of functional receptors for ciliary neurotrophic factor on neuronal cell lines and primary neurons. Neuron 5:757-766.

Stockli KA, Lottspeich F, Sendtner M, Masiakowski P, Carroll P, Gotz $\mathrm{R}$, Lindholm D, Thoenen $\mathrm{H}$ (1989) Molecular cloning, expression, and regional distribution of rat ciliary neurotrophic factor. Nature 342:920-923.

Studier FW, Rosenberg AH, Dunn JJ, Dubendorff JW (1990) Use of T7 RNA polymerase to direct expression of cloned genes. Methods Enzymol 185:60-89.

Taniuchi M, Clark HB, Schweitzer JB, Johnson EM Jr (1988) Expression of nerve growth factor receptors by Schwann cells of axotomized peripheral nerves: ultrastructural localization, suppression by axonal contact, and binding properties. Proc Natl Acad Sci USA 8: 664-681.

Torigoe K (1988) Terminal sprouting in partially denervated muscle of the mouse: a scanning electron microscopic study. J Neurocytol 17:563-571.

Wanaka A, Johnson EM Jr, Milbrandt J (1990) Localization of FGF receptor mRNA in the adult rat central nervous system by in situ hybridization. Neuron 5:267-281. 